\title{
Neuroscience and Didactic Principles and Implications of Brain-Based Teaching and Learning
}

\author{
Hans Schachl
}

\begin{abstract}
The article deals with the role of neuroscience in education. For educational purposes, it is crucial to know how the brain works as learning is a brain-based activity. In the article, the reader can also find the basic brain-based teaching principles.
\end{abstract}

Key words: neuroscience, neurodidactics, brain, learning, teaching principles

\section{Introduction}

"Neuro" is one of the dominant "trends" in many disciplines: neuromarketing, neuroethics, neurodidactics, etc. In the last decades, the insight into the brain has dramatically improved thanks to new techniques, which enable us to look into the living brain, not only after the death of a person. Brain research brings more and more results about learning, too.

The answer on the question "What do we have in our heads?" (Schachl, 2006) is very important for teaching and learning in general and for universities, too. Teaching and learning are brain based activities because learning is done by the brain.

To clarify the brain processes with learning, we have to deal with the following questions, "How do information get into the brain?"; "What is the role of emotions?"; and finally, "How is information stored?".

\section{How is information fed into the brain?}

Gaining knowledge is an active process. For example, if several persons look at a picture, the background of the eyes (the retina) transforms the energy of the light into electrical energy in the nerve cells, which deliver this electrical information via optical nerves to the backside of the brain. There the information concerning edges, contrast, dark or light sides, colours, and angles is analysed.

\footnotetext{
* Hans Schachl, Private Pädagogische Hochschule der Diözese Linz, Linz, Austria; hans.schachl@ph-linz.at
} 
In all brains, it is the same until here, but sometimes there are big differences in the interpretation of visual information, as creating the real image is a mutual process of analysing and comparing with expectations, context, attitudes, available knowledge, etc. Perception is therefore a subjective, constructive process.

The dependence of perception on the individual leads to problems in human relationships, to misunderstandings between nations and even to wars. Everyone is convinced that the truth is on their side. The recognition of this subjectivism is important for teaching, educating, and learning, too; the reception of information depends on attitudes, education, environment, pre-knowledge, pre-information, context, structure, and, finally, on the whole personality of the individual (curiosity, interests, self-confidence, patience, controlling emotions, attention, readiness for cooperation, intelligence, motivation, etc.).

From the above mentioned, the following "basic principles of teaching and learning" (they are relevant for universities, too) can be derived (Schachl, 2006 and 2010):

- Overview before details

- Multi-sensory approach

- Take previous knowledge into consideration

- Contextual learning

- Interdependence of knowledge areas

\section{How can the learner be switched to reception?}

It depends on the attention whether information gets into the brain or not. What factors influence attention? Of course, it is a very important topic for teaching and learning. Attention is influenced by the individual's expectations, interest in the topic, attitudes, context, but it also depends on the kind of teaching, presenting information in a suitable way, etc. For managing attention, a region in the depth of the brain - the reticular formation (formation reticularis) - is very important.

All kinds of information come either from the inside or from the outside of the body. All these stimuli travel via the reticular formation and are processed to the limbic system responsible for emotions; there is an impact on the autonomic nervous system (hypothalamus). 


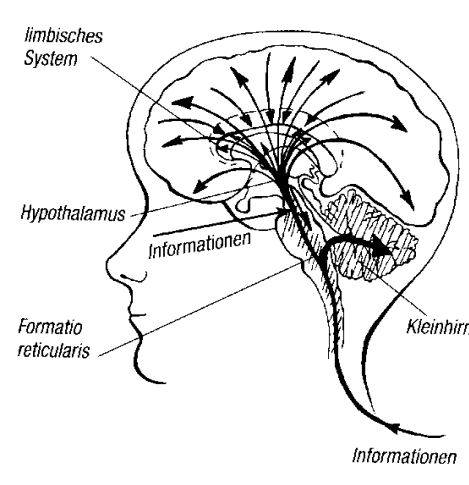

If the information is exciting, blood pressure and the heart beat increase, the hands sweat, etc. The cerebellum is responsible for a good muscular state (for instance of the head) in order to be able to listen carefully.

Finally, the cerebral cortex is consciously aware. This does not only mean attention is a conscious process, but that the deeper brain is involved very intensively. Therefore, for improving attention, it is necessary to do something for all these parts of the brain.

(Schachl, 2006, p. 55)

The following "basic principles" may help:

- Stimulate interest and curiosity.

- Teach attractively and in varieties.

- Teach with enthusiasm ("Enthusiastic teachers fill learners with enthusiasm").

- Use different perception channels.

- Take care of conscious attention.

- Enable movement and breaks.

- Take care of feelings.

Especially the last one is very important.

\section{The role of emotions}

Rationality and emotionality are often discussed as two separate issues but such a separation does not exist in the brain. Therefore, especially for the purposes of teaching and learning, we have to look at emotions and cognition as working closely together.

(Roth, 2011, p. 323)

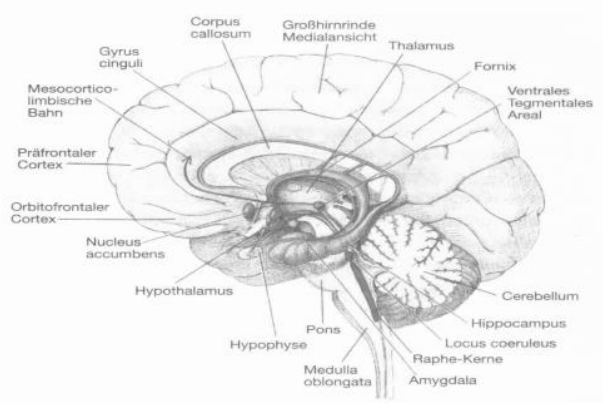


Feelings and emotions have a strong influence on learning. For emotions, the limbic system consisting of different parts of the brain is the most important structure. Some parts of this system are like "connecting links" between the cognition and emotions.

The amygdala (almond) is an emotional marker of contents on the way to the long-term memory and evokes anxiety, fear, and joy. It plays a significant role in recognizing the emotional signals in mimic expressions (Roth, 2011).

The mesolimbic system (nucleus accumbens, ventrales tegmental area) is the central "rewarding-system and rewarding-memory" for motivation, interest, etc. (Roth, 2011, p. 444; Stuber et al., 2011). Therefore this system is very important for learning. The working chemicals are called endogene opiods (endorphins) and dopamine (Rossato et al., 2009). The dopaminer nerve cells (neurons) fire with expected and unexpected rewards but if expected rewards do not occur, the relevant chemical reaction does not occur either (Cohen et al., 2012, pp. 85-88).

The orbitofrontal cortex is responsible for controlling behaviour, moral and ethics (Roth, 2011, p. 45). The prefrontal cortex (PFC) is considered the center of the "working memory" (Wang, 2011) and also of intelligence. These interpretation of PFC as a "location" is being criticised and the PFC is seen as a kind of "attentional filter" of memory (Wolf, 2009, pp. 56-61). The PFC is essential for introspection and metacognition, too (Fleming et al., 2010).

The hippocampus is of an utmost importance, this part of the brain is responsible for storing information in the long-term memory and also for retrieving (together with prefrontal cortex) and consolidating it (about 2 - 6 weeks after learning), but it is not the long-term memory itself. It acts like a working memory (Roth, 2011, p. 109; Miller, 2008b; Gelbard-Sagiv, 2008). Shortly, the reception of information is managed by the hippocampus and is followed by its consolidation by the prefrontal cortex. The prefrontal cortex and the hippocampus cooperate when retrieving information (Takehara-Nishiuchi and McNaughton, 2008).

It is a clear fact that if the hippocampus is damaged or it does not work anymore, one cannot learn anything new. It is, for instance, the case with the Alzheimer's disease - these people ask you the same question ten times in half an hour because they cannot store the answer. They have a "moment to moment" consciousness.

The hippocampus has a double function; it is also important for emotions (Roth, 2011, p. 110), which means that emotions influence storing information and vice versa, the memory influences the perception and the retrieval of emotions. This double function is also evident in the chemical processes inside; for the entrance of new information into the long-term memory dopamine-mechanisms, controlled by a specific part of the hippocampus, are important (Rossato et al., 2009, pp. 1017-1020). Training and learning are also associated with changes in the density of the cortical dopamine receptors (McNab et al., 2009, pp. 800-802). The additional tasks of the hippocampus are as follows: 
- The hippocampus (especially the right posterior part) plays an important role with spatial orientation which is developing with experience. There is an impairment of this task following the so called transient global amnesia (Bartsch et al., 2010). The hippocampus is also involved in action planning (Pastalkova et al., 2008).

- Parts of the prefrontal cortex and of the hippocampus are involved in the so called "reinforcing- and rewarding-learning" mediated by dopamine (Luo et al., 2011; Stuber et al., 2008).

Stress causes an increased release of the cortisol hormone in the hippocampus, too (Lederbogen et al., 2011). With long-lasting, chronic stress, cortisol impairs nerve cells in the hippocampus (Roth, 2011, 52; Kaouane et al., 2012) and so the ability to learn.

Emotions play an important role in teaching and learning at university level, too. Cognition and emotions are not separated; they work together even in the anatomical structure and via chemical processes. Positive emotions and the anxiety and stress reduction are a "must" in learning.

All learning is senseless if the joy is lost (Pestalozzi). Learning does not always have to be fun, joy can also come from the challenge and the reward after hard work.

Yet, teachers must keep in mind that anxiety and stress are adverse to learning. Based on the above mentioned, we can formulate the following principles for teaching:

- Foster positive emotions.

- Arouse interest.

- Involve breaks (especially for physical exercises) in the teaching sessions.

- Avoid anxiety and give advice for coping with stress.

\section{How is information stored?}

It is clear that memory does not work like a card box, computer file, or a CDROM. Trying to answer the question "How information is stored?" must be based on understanding of the functioning of the units of the brain, the cells. The power of the human brain can only be explained by the gigantic number of nerve cells. More than 100 billion neurons (15.000.000.000 of them in the upper layer, the Cortex) are interconnected, and in between these neurons there are double more glia cells. All the nerve cells work nearly according to the same principle information comes into the cells via many nerve fibres (dendrites). The cell body processes this information and gives the result via one fibre (axon) to other 


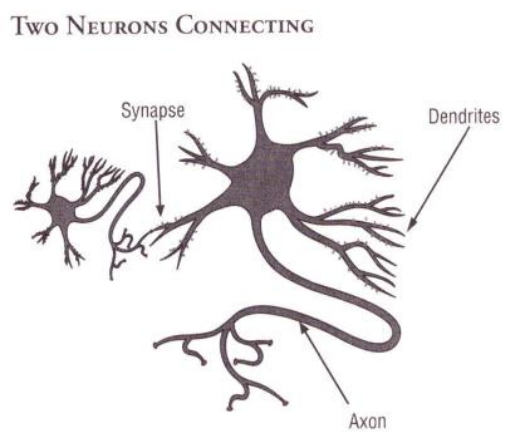

(Jensen, 2005, p. 17) neurons. The connecting place between cells is called the synapse. The axon mostly has many branches, so that the information can be distributed to many other cells by $500-20.000$ synapses per neuron that means more than 100.000.000.000.000 of them (Zimmer, 2011). This "one way" communication is a bit more complicated, because there is also communication between the dendrites, which is like a "tuning" for the neurons (Lazvin et al., 2012).

What happens with learning? Very shortly, learning makes the network of nerve cells stronger, thicker, faster, and more stable. In detail, it means that sprouting of dendrites increases the number of synapses, strengthens and stabilizes the synapses; and what is surprising and fascinating, there is also neurogenesis that means that new neurons are built (Berninger and Götz, 2009, pp. 58-63; Shors, 2009, pp. 41-48; Ma et al., 2009, pp. 1074-1077). Meanwhile, there is scientific evidence, that all this is possible even in adult age (Sahay et al., 2011). Of course, this "neuroplasticity" decreases with age.

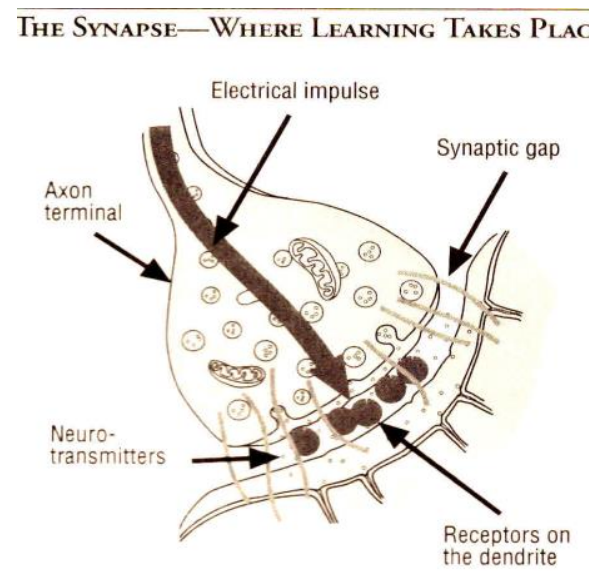

(Jensen, 2005, p. 18)
For a deeper understanding of the neurobiological processes with learning, it is important to go deeper and to ask what happens inside the synapses, what makes them "thicker". At the synaptic gap, the information (via electrical impulse) is transformed into chemical tracers (so called neurotransmitters, e.g. glutamate), which transfer the message to the other side of the gap.

At the postsynaptic side, the receptors are opened by the transmitter, which steers a cascade of chemical processes for storing the information. Thereby the production of proteins is very important as memory is chemical. For exploring the processes at the synapse, Kandel (see Kandel, 2006) recieved the Nobel Prize. 
Some findings show that at the postsynapse, there is no fixed position of receptors, but there is a "highly dynamic structure" with the possibility "to refresh itself rapidly" by an exchange of the used receptors against the unused ones (Silver and Kanichay, 2008, p. 183).

It is very interesting and complicated that on one synapse not only one transmitter can be released, but two, like dopamine (an excitatory transmitter) with GABA (an inhibitory one). That means that the balance between the excitatory and the inhibitory processes can be managed at cell level (Williams, 2012, p.178; Tritsch et al., 2012, pp. 262-266).

The processes are far more complicated because the GLIA-cells play a significant role in this game (Allen and Barres, 2009, pp. 675-677). The glia (with different cell types) is responsible for many jobs (nutrition, stabilizing, myelination, and immune-activities). Among those types, the oligodendrocytes are responsible for myelination, which is very important during the process of nervous system development (until the third decade of our life). Healthy myelin is essential to higher order cognitive functions (Nave, 2010).

Nowadays, there is an evidence that especially one kind of glia cells, the so called astrocytes, have an important function in producing and managing mental abilities. This makes sense in relation to the huge number of glia cells and also to the fact, that there is an interesting difference in astrocytes between humans and other mammals - astrocytes are much more complex in the human cortex than those of other mammals. The astrocytes seem to be involved in the synapse formation process, in axon pruning, synapse elimination, and in modulating synaptic functions through communication with neurons (Eroglu and Barres, 2010).

The classical form of long-term memory processing relies on some specific receptors (the so called NMDA-receptors) at the postsynaptic side. The astrocytes release - dependent on Calcium - the so called D-serine, which is a co-worker of these specific NMDA. A repetitive synaptic activity enhances the $\mathrm{D}$-serine supply by the astrocytes which is a strong argument for repetition in the learning process (Henneberger et al., 2010, pp. 232-236; Santello and Volterra, 2010, pp. 169 - 170).

As for memory, there are some basic principles of teaching and learning:

- Repeating the learning matter leads to repeated electrochemical processes in the nerve circuits and strengthens them. The contents must be the same or very similar in order to reactivate them precisely (Xue et al., 2010).

- Giving Feedback is very important. It is always more difficult to correct what has been learnt than to learn it right from the beginning. In order to produce right chemical memory traces, it is necessary to give feedback as soon as possible. In case of positive feedback with reward, the strength of synapses is increased by chemical processes.

- Even the prognosis of a reward can have a positive effect (Stuber et al., 
2008).

- Linking ideas and topics to structures - memory consolidation can be fostered very strongly if an associative scheme is provided into which new information can be incorporated. So, teachers must underpin these processes by establishing schemas, patterns, framework, and structures.

- Taking breaks is necessary to give these chemical processes time to work.

All the mentioned methods and principles are included in the "overall principle": the brain needs sense.

Teachers must keep the students motivated as the learners should be convinced that the topic is meaningful and they must understand the content. That means that teachers should give high-quality presentations with good visualizing, etc. And lastly, information should be integrated into associative networks, not presented as isolated facts.

\section{Summary}

The basic principles of brain-based teaching are (Schachl, 2006):

- Present an overview before details.

- Use a multi-sensory approach.

- Take previous knowledge into consideration.

- Initiate contextual learning and show the interdependence of knowledge areas.

- Stimulate interests and curiosity.

- Arouse interest and teach attractively and in varieties.

- Teach with enthusiasm (,Enthusiastic teachers fill learners with enthusiasm").

- Take care of conscious attention.

- Take care of feelings and foster positive emotions.

- Involve breaks (in particular for physical exercises) in the teaching sessions.

- Avoid anxiety and give advice on coping with stress.

- Initiate repetition.

- Give feedback as soon as possible.

- Link ideas and topics into structures. 


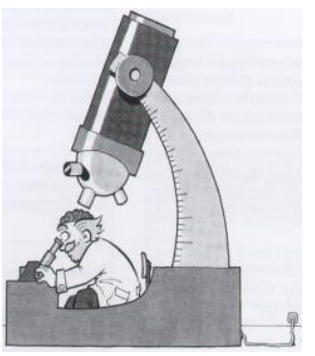

(Schachl, 2006, p. 10)

Is there a real contribution of brain research? Most of these "principles" are "old teachers' wisdom" but this knowledge of good, experienced teachers is now based and proved on brain-research findings. Therefore teachers cannot simply reject them arguing that they can choose the methods they want to use. These principles are not only "guidelines", but they are the "basics".

Brain research has made a great progress in the last twenty years, but nevertheless it is just the beginning. Of course, an interdisciplinary approach for exploring learning, including all kinds of scientific fields (linguistics, brain research, psychology, philosophy, etc.), is necessary. Research on the brain processes is important for improving learning, understanding contents, and in order to contribute to a better world. In the $17^{\text {th }}$ century, Comenius formulated the need for education very clearly, "The goal is, that in schools (and of course in universities, too) there must be less noise, less frustration, less boredom, and no useless work, but more freedom, more joy, more happiness, and therefore more real success!"

\section{Literature:}

ALLEN, N. J. and BARRES, B. A. Glia - more than just brain glue. Nature, 2009, $675-677$.

BARTSCH, T. et al. Focal Lesions of Human Hippocampal CA1 Neurons in Transient Global Amnesia Impair Place Memory. Science, 2010, 1412-1415.

BERNINGER, B. and GÖTZ, M. Nachwuchsförderung im Gehirn. Gehirn\&Geist, 7-8, 58-63.

CARTER, R. Das Gehirn. München: Dorling Kindersley. (English version: The Brain Book, 2009, London: Dorling Kindersley).

COHEN, J. Y. et al. Neuron-type-specific signals for reward and punishment in the ventral tegmental area. Nature, 2012, 85-88.

DAHLIN, E. et al. Transfer of Learning after Updating Training Mediated by the Striatum. Science, 2008, 151-512.

EROGLU, C. and BARRES, B. A. Regulation of synaptic connectivity byglia. Nature, 2010, 223-231.

FLEMING, S. M. et al. Relating Introspective Accuracy to Individual Differences in Brain Structure. Science, 2010, 1541-1543.

Gehirn\&Geist Spezial 2011. Entdeckungsreise durch das Gehirn. 1/2011.

GELBARD-SAGIV, H. et al. Internally Generated Reactivation of Single Neurons in Human Hippocampus during Free Recall. Science, 2008, 96-100. 
HENNEBERGER et al. Long-term potentiation depends on release of D-serine from astrocytes. Nature, 2010, $232-236$.

JENSEN, E. Teaching with the brain in mind. 2nd Edition, Revised and Updated. Alexandria: ASCD, 2005.

KANDEL, E. R. In Search of Memory. The Emergence of a New Science of Mind. New York: Norton. 2006.

KAOUANE, N. et al. Glucocorticoids Can Induce PTSD-Like Memory Impairments in Mice. Science, 2012, 1510-1513.

LAZVIN, M. et al. Nonlinear dendritic processing determines angular tuning of barrel cortex neurons in vivo. Nature, 2012, 397-401.

LEDERBOGEN, F. et al. City living and urban upbringing affect neural social stress processing in humans. Nature, 2011, 474, 498-501.

LEMOS, J. C. et al. Severe stress switches CRF action in the nucleus accumbens from appetitive to aversive. Nature, 2012, 402-406.

LUO, A. H. et al. Linking Context with Reward: A Functional Circuit from Hippocampal CA3 to Ventral Tegmental Area. Science, 2011, 353-356.

MA, D. K. et al. Neuronal Activity-Induced Gadd45b Promotes Epigenetic DNA Demethylation and Adult Neurogenesis. Science, 2009, 1074-1077.

$\mathrm{McNab}, \mathrm{F}$. et al. Changes in Cortical Dopamine D1 Receptor Binding associated with Cognitive Training. Science, 2009, 800-802.

MILLER, G. Reflecting on Another's Mind [online]. 2008a. Available from: http://www.sciencemag.org/cgi/content/full/308/5724/945

MILLER, G. Hippocampal Firing Patterns Linked to Memory Recall. Science, 2008b, 1280-1281.

NAVE, K. A. Myelination and support of axonal integrity by glia. Nature, 2010, 244-252.

PASTALKOVA et al. Internally Generated Cell Assembly Sequences in the Rat Hippocampus. Science, 2008, 1322-1327.

RIZZOLATTI, G., FOGASSI, L. and GALLESE, V. Mirrors in the Mind. Scientific American, 2006, 11, 30-37.

ROSSATO, J. I. et al. Dopamine Controls Persistance of Long-Term Memory Storage. Science, 2009, 1017-1020.

ROTH, G. Bildung braucht Persönlichkeit. Wie Lernen gelingt. Stuttgart: KlettCotta, 2011.

SAHAY, A. et al. Increasing adult hippocampal neurogenesis is sufficient to improve pattern separation. Nature, 2011, 466-470.

SANTELLO, M. and VOLTERRA, A. Astrocytes as aide-memories. Nature, 2010, $169-170$.

SCHACHL, H. Lernen ohne Angst. Mehr Freude und Erfolg in der Schule. Wien: Bundesministerium für Unterricht und Kunst, 1991.

SCHACHL, H. Was haben wir im Kopf? Die Grundlagen für gehirngerechtes Lehren und Lernen. $3^{\text {rd }}$ revised edition. Linz: Veritas, 2006. 
SCHACHL, H. What's in our head? Principles and implications of brain-based teaching and learning. Nitra: University of Nitra, 2010.

SHORS, T. J. Saving New Brain Cells. Scientific American, 2009, 41-48.

SILVER, R. A. and KANICHAY, R. T. Refreshing Connections. Science 2008, 183-184.

SPITZER, M. Lernen. Gehirnforschung und die Schule des Lebens. Heidelberg: Spektrum Akademischer Verlag, 2002.

STIX, G. How to build a better learner. Scientific American, August 2011, 3037.

STUBER, G. D. et al. Reward-Predictive Cues Enhance Excitatory Synaptic Strength onto Midbrain Dopamine Neurons. Science, 2008, 1690-1692.

STUBER, G. D. et al. 2011. Excitatory transmission from the amygdala to nucleus accumbens facilitates reward seeking. Nature, 2011, 377-380.

SWAMINATHAN, N. New Neurons in Old Brains Exhibit Babylike Plasticity [online]. 2008a [viewed 21 February 2008]. Available from:

http://www.sciam.com

SWAMINATHAN, N. Is Old Age Memory Decline Reversible? [online]. 2008b [viewed 21 February 2008]. Available from: http://www.sciam.com

TAKEHARA-NISHIUCHI, K. and MCNAUGHTON, B. L. Spontaneous Changes of Neocortical Code for Associative Memory during Consolidation. Science, 2008, 960-963.

TCHERNICHOVSKI, O. and WALLMAN, J. Neurons of imitation. Nature, 2008, 451, 249f.

TRITSCH, N. X. et al. Dopaminergic neurons inhibit striatal output through non-canonical release of GABA. Nature, 2012, 262-266.

TRNIKOVÁ, J. and PETLÁK, E. Neuroscience as a Basis for Innovations in Education. Acta Technologica Dubnicae, 2012, 4, 43- 51.

TSE, D. et al. Schemas and Memory Consolidation [online]. 2008 [viewed 21 February 2008]. Available from: http://www.sciencemag.org

TSE, D. et al. Schema Dependent Gene Activation and Memory Encoding in Neocortex. Science, 2011, 891-895.

WANG, M. et al. Neuronal basis of age-related working memory decline. Nature, 2011, 210-213.

WILLIAMS, J. T. Promiscuous vesicles. Nature, 2012, 178-179.

WOLF, C. Flüchtige Erinnerung. Gehirn \& Geist, 2009, 4, 56-61.

XUE, G. et al. Greater Neural Pattern Similarity Across Repetitions Is Associated with Better Memory. Science, 2010, 97-101.

ZIMMER, C. 100 Trillion Connections. Scientific American, January 2011, 4549. 